\title{
CRM Systems Management of Metallurgical Companies in Kazakhstan Based on the TRI * M System Methodology
}

\author{
Arman Islamgaleyev ${ }^{1, *}$ \\ ${ }^{1}$ Kazpromkompleks LLP, Pushkin St. 55/2, 010008 Nur-Sultan, Kazakhstan
}

\begin{abstract}
The article presents material on the practical implementation of CRM programs in metallurgical organizations and the experience of its usage. In the result of the study, an attempt was made to generalize the configuration of the CRM approach to relationships and programs accounting, as well as typical impressions of the entire CRM implementation process using as integrated platform for the stakeholders in the form of TRI * M system an analytical tool.
\end{abstract}

\section{Introduction}

A management system model using a customer-oriented approach involves a combination of three configurations:

1. Determining the level of management of the interaction of the enterprise with the customer, which includes:

- complex of customer acquisition management;

- customer service management complex;

- customer retention management system.

2. Database management, as two separate management levels of the Target Client Group and the Client Base, which contributes to the implementation in practical activities of the enterprise with customer centric marketing business concepts.

3. Synchronization of CRM software with accounting policies.

When developing a customer-oriented approach from the point of view of forming and evaluating an appropriate set of qualities in relations with customers, applied and scientific problems are formed and these problems are associated with the formation of the theory, methodology and the development of methodological tools that companies develop independently and in different directions in CRM systems. In addition, it is necessary to develop methods for creating and evaluating CRM systems, as well as tools for determining the effectiveness of building customer relationships. This also translates into enterprise innovation [1]. It also contributes to the innovation of the economy [2].

Currently, there are customer retention systems, in particular, it is a TRI * M system. Introducing a comprehensive platform for stakeholders in the form of 5 analytical tools: TRI * M Index, TRI * M Typology, TRI * M Grid, TRI * M Competitive Analysis, TRI *

${ }^{*}$ Corresponding author: ax@kazprom.com 
M Conversion Model and considers the ability to retain consumers, as well as emotional and behavioral barriers.

\section{Literature review}

During the study, the following sales management models for metallurgical sector companies were analyzed and systematized, as presented in table 1 .

Table 1. Company's sales management models

\begin{tabular}{|l|l|}
\hline Model & Description of Models \\
\hline $\begin{array}{l}\text { Pipeline Sales } \\
\text { Model LG-LC-AM }\end{array}$ & $\begin{array}{l}\text { This model provides for segmentation of customers by frequency of } \\
\text { purchases, determination of the functionality of sales staff, their motivation } \\
\text { and training. }\end{array}$ \\
\hline Model «Net 2 Net» & $\begin{array}{l}\text { Support and assistance by the company of its customers on geographically } \\
\text { distant projects. }\end{array}$ \\
\hline $\begin{array}{l}\text { "Service } \\
\text { Integrator" Model }\end{array}$ & $\begin{array}{l}\text { Part of the CO closure program and includes: } \\
\text { - Development of pipeline projects architecture and regulatory industry } \\
\text { software. } \\
\text { - Monitoring project expertise. }\end{array}$ \\
\hline $\begin{array}{l}\text { Model "Package } \\
\text { Service Offer" }\end{array}$ & $\begin{array}{l}\text { The basis of this proposal lies in the plane of creating a unique system for } \\
\text { processing customer orders, which allows delivering metal to the consumer } \\
\text { faster than competitors do and creates a competitive advantage for itself. }\end{array}$ \\
\hline $\begin{array}{l}\text { "Service metal } \\
\text { center" Model }\end{array}$ & \begin{tabular}{l} 
Warehouse complexes are equipped with special metal processing equipment. \\
\hline Metal processing
\end{tabular} Combination of sales of metal with the provision of metalworking services. \\
\hline $\begin{array}{l}\text { Structured Sales } \\
\text { Model }\end{array}$ & $\begin{array}{l}\text { A reference to the maximum index of penetration and customer reach, } \\
\text { increasing efficiency and competitiveness, and the speed of response to } \\
\text { changing market conditions. }\end{array}$ \\
\hline
\end{tabular}

Source: [3-6]

CRM software products have several basic types in terms of their practical use.

The first, the large group is CRM programs that operate in isolation from accounting programs, that is, "completely independent from accounting." Why is it necessary - this is when customers, operations, transactions do not need to be reflected in accounting (in the context of each customer). This, for example, retail customers - buyers of super- and hypermarkets, or individuals - customers of banks. As a rule, in this case, the customers do not need to issue invoices, it is not necessary to keep records of transactions separately for each customer in the accounting database. CRM software performs the functions of accounting for these persons (without name, by discount card number), sending them advertising by mail, analyzing sales of products and services, collecting big data, holding stocks, etc. [6-9].

Interaction with accounting is critical for the second group of CRM software. When it needs quickly, literally within an hour, to see the payment of the customer or supplier or necessary quickly carry out reconciliation acts, and this often changes quickly throughout the day and there is absolutely no time for numerous tedious synchronization. When there is no time for heavy and tedious "exchanges between bases", during which it is impossible to work in both bases in contact with each other. There is no time for "raking" the various conflicts and inconsistencies that are found in the exchange process. It is difficult to achieve full-fledged work without accounting, in a purely managerial, "trading" program, as if it is "separate from accounting" [10-11].

The second group of CRM software is much more useful, convenient and practical. Therefore, if customer accounting capabilities built directly into the accounting system without unnecessarily time-consuming exchanges between different programs, this is 
simply priceless. Unfortunately, now, CRM capabilities in conjunction with accounting in the Republic of Kazakhstan are an exception rather than a rule. The simultaneous use of CRM customer accounting is an unprecedented curiosity rather than a constant practice, and this is a very rare occurrence in the Republic of Kazakhstan.[12-13].

\section{Materials and methods}

A review of the materials on the practical implementation of CRM programs in various organizations and the experience of its use, showed:

- Managers'errors of in maintaining the CRM database.

1) Managers usually start an asset classification system, as they need it to upload from a CRM system to an online store. In the accounting, financial system the classification of assets usually conducted in a completely different way.

2) Managers lead counterparties in a completely different way, unlike an accountant. Also managers usually do not know the rules for posting taxes on individuals. In addition, they often do not indicate important characteristics of the counterparty (BIN, TRN, official name, etc.), which is reflected the incorrectness in the accounting system. They may formduplicate counterparties, without paying attention to the availability of existing ones. They process incorrectly renaming the counterparty. There is lack of interpretation at a strict accounting level. All of these lead to the end of "CRM revolution".

3) Duplication of information (counterparties, accounts, etc.) in the CRM database, which lead to errors and desync, even with the most careful and accurate maintenance of the CRM database.

Evaluation of the effectiveness of CRM for each element quality and its position in the TRI * M Grid shows where the company should operate in order to increase the impact on customer retention by improving relationships with stakeholders and identifying synchronization with all enterprise systems. The research carried out in the company Kazpromcomplex LLP

- TRI * M Index 101

- TRI * M Typology, customer resistance coefficient is 3.4

CRM synchronization parameters and its effect on customer retention reflected in the areas of:

- Motivators - keys to keeping customers

- Hidden opportunities - to differentiate and develop future benefits

- Prospects

- Potential savings, where the company is concerned about the quality of the elements of interaction

List of questions for company management and programmers.

1. Evaluate the effectiveness of your work as a manager in a CRM system. Do you achieve your management goals using the CRM system?

2. Evaluate the appropriateness of maintaining in the CRM system a repeated, duplicate information on payment accounts, counterparties, if the same information is available in the accounting system.

3. What do you think, is a CRM system capable of replacing completely an accounting system (suppose that such a possibility exists in a CRM system)?

4. Do you think that managers are able to keep records of mutual settlements with counterparties and the movement of money in the CRM system completely independently from accounting department(suppose there is such an opportunity in the CRM system)?

5. Do you think that managers are able to maintain warehouse records, shipments and goods receipts completely independently from accounting department in the CRM system (suppose that such a possibility exists in the CRM system)? 
6. Do you think that managers are ableto record address and contact information about customers, tax details, etc, completely independent from accounting department, in the CRM system (suppose there is such a possibility in the CRM system)?

7. Do you think that managers are able to conduct logistics and supply management completely independently from accounting department in the CRM system?

8. Given the answers to the above questions, what is left for CRM systems?

\section{Results and discussions}

The actiogram of management activity in CRM is shown in Figure 1.

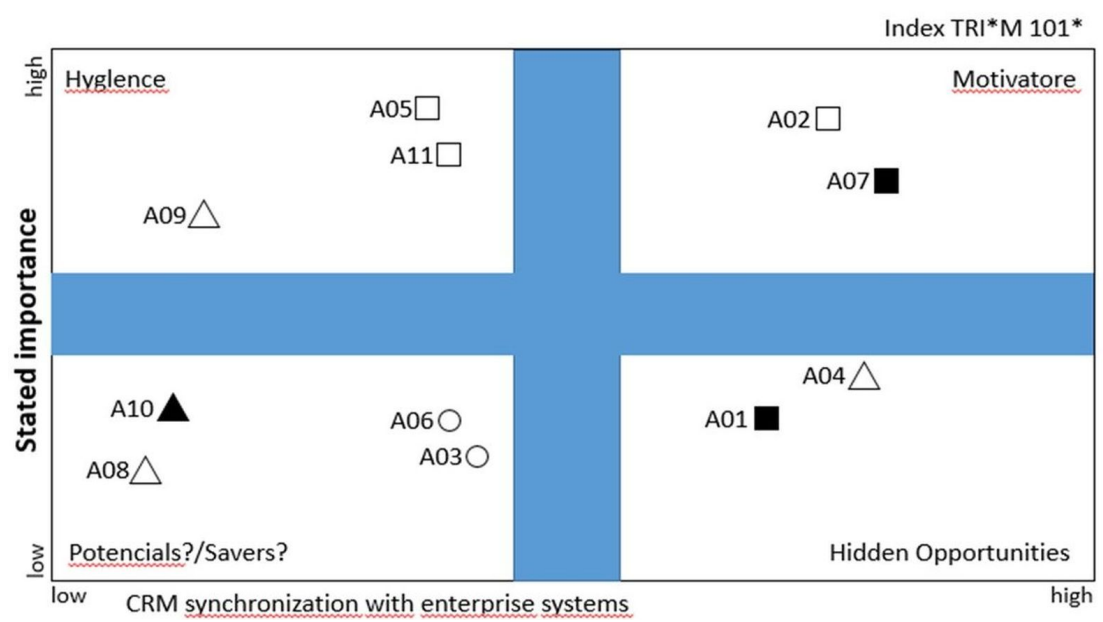

Fig. 1. TRI * M Grid Source: [13].

Note:

A01 Manager Performance in a CRM system

A02 Duplication of information with paired systems

A03 CRM replacement for all enterprise operating systems

A04 Quality of Planning Activities at CRM

A05 Presale Service

A06 After Sales Service

A07 Billing

A08 Complaints and Reclamations considering

A09 Interaction with Logistics and Procurement, SCM

A10 Interaction with accounting

A11 Electronic document management

1) "Clients" - the main objects of accounting of CRMsoftware.

By "client" means a buyer, a specific sales manager of the companyisresponsible for relation with him.

The first and main mistake in the field of CRM is an attempt to separate the "clients" (customer) from the "counterparties" entity, creating an artificial phantom entity "client" ("buyers"). This happens because the IT employee ("automation engineer") listens attentively to the sales employee ("manager"), and then mistakenly assumes that the "manager" is an expert in his field, and singles out the entity category "client" in his words. Then he creates a separate directory "Clients", where the problems begin.

Synchronization of this new directory "Clients" with "Counterparties" is a constant problem. Further, in addition, the "client" can sometimes temporarily act in other roles, for example, as the "customer". What to do in this case? Then, the following roles arise (which 
the incompetent "expert" sales manager ignored or forgot) - "supplier", "state agency", "intermediary", "carrier", and so on ad infinitum, and is it means to create a separate directory for each role with constant synchronization?

2) "Contracts" (transactions, contracts, specifications, applications, orders, etc.) are also the main objects of CRM software.

The second most common mistake of the "automation engineer", which unnecessarily relied on the competence of the "expert sales manager", is the unreasonable fragmentation of a single entity "contract" into various phantom pseudo entities, for example, "transaction", "contract", "specification", "application", "Trade agreement", "order", etc. All these are simply different "contract roles" (understood in the traditional accounting sense). In addition, it is necessary to operate with all these contract roles according to uniform rules. However, if imprudently believe to the "expert sales manager" and make all these objects as separate entities in the program, then can arise exactly the same problems.

In fact, a "transaction" is the same contract at the level of preliminary discussion and execution. "Contract" is an already signed contract. "Specification" is a list of goods and materials supplied in this delivery. It applied, when concluding a framework contract, it is impossible to foresee a specific list and quantity of goods and materials that will subsequently delivered. An "application" is the same as a specification. An "order" usually called a contract with a buyer, sometimes for the performance of work or services in conjunction with the supply of goods and materials.

Moreover, there can be quite a lot of such contract roles, and it is better to leave the list of these roles open for adding new contract roles at the user level.

Thus, reducing all these "mysterious" terms to different "contract roles" simply eliminates confusion and makes the situation around CRM understandable to most accountants and accounting specialists. All these "riddles" are simply contracts at different stages and conditions of their execution, existence, closure. As soon as ordinary accountants understand this truth, immediately in the CRM area, there will be nothing mysterious and incomprehensible for them that supposedly requires some kind of separate accounting program and / or any separate program from accounting.

Sometimes the ideas of breaking up "orders" into "potential orders", "pre-orders", "orders at work", "applications", "plans", etc. still widely promoted. Again, for each type of order, these various entities are documents or reference books, and then subsequently there will be many problems with their synchronization. These pseudo-entities are phantom, and these are all just "stages of the contract / order / document", understood as the requisite of the "Stage" type of the reference book "Stage of the document / order / contract".

Agreement and subcontract (conditional term).

However, it is not so easy to deal with the variety and complexity of the existing contractual relationships between suppliers, customers, carriers, intermediaries, etc. Established suppliers sometimes require adherence to their naming scheme and terminology - the "main contract", and the "appendix" or "specification" to it. In this case, it can declared as "application" or "specification" as a "subcontract" (conditional term). A "subcontract" by type is also a contract, but tied to a "main contract" that acts as a "framework contract" without a list of goods and materials, and a subcontract drawn up each time in order to specify the list of goods and materials in a particular delivery by a certain date. If such a scheme is used, not only the contract, but also the subcontract indicated in the primary documents. At the same time, real postings are made only under the main contract (otherwise, according to analytics, "contract" in accounting will be a terrible confusion), and the "subcontract" field in the document is used for additional analytical accounting, usually in the context of monthly deliveries.

Another serious mistake made by "automation engineers" and "sales experts" is a misunderstanding of the crosscutting complex nature of all relationships at the enterprise. 
Accounting only with customer relations (CRM) makes little sense and almost no use if it carried out without interconnecting orders from customers with applications and specifications for suppliers (SCM), with procurement plans from suppliers. Accounting in CRM software only customers is unproductive and makes sense only where the product supplied by the company is usually unlimited and / or there is no need to interconnect customer orders with procurement plans from suppliers (bank customers, customers of retail super- and hypermarkets). However, such a situation of "unlimited supply" is rare.

Features of the behavior of various groups of people in the enterprise.

When introducing a ready-made CRM software or creating it from scratch in an enterprise, usually there are several user groups whose interests and behavior considered.

The first group is the first leader / managers and chief accountant. Without firm and constant support of at least one of them, the CRM software implementation project is obviously doomed to failure.

A group of deputy chief accountants and ordinary accountants may experience some inconvenience due to the implementation of the new CRM software. Poorly designed CRM software systems may require duplication of contracts, payments, or ongoing data interchanges (if CRM software implemented "separately from accounting").

The next group is sales managers. As experience shows, they are at least wary of implementing CRM software. If before CRM software, all customer data was in the form of varied files at the sole disposal of the sales manager, now all of them are consolidated and many errors, long-standing problems become visible, defects are detected, etc. Of course, all this causes hostility to the new system. Additionally, with the start of the transition to CRM software, sales managers often feel insecure about the preservation of their jobs, because usually any automation causes their reduction.

However, usually the mood of sales managers changes over time. They discover new opportunities that have appeared with the advent of the new CRM software. For example, they can see customers of another manager, when another manager fired, they have the right to rely on his "orphaned" customers, search for potential new clients based on somewhere lost "no-one" or "one-time" customers, they can leave the manager on vacation to replace, etc.

Another group is purchasing managers. At the beginning of automation, they are confident that this will not affect them at all. However, eventually it becomes clear that without the link "customers - contracts with customers - our company - suppliers - contracts with suppliers" automation only gives little to customers. Usually the first step in a new publicity is the Procurement Plan.

A group of individual employees with special powers - personnel officer, lawyer, etc. can be both supporters of the new CRM software system and its opponents. The lawyer may be uncomfortable due to the "new publicity" of agreements that were previously hidden on the computer of the lawyer and are available only with his notification.

The warehouse inventory team may also experience discomfort due to complicated requirements for processing shipping documents. If earlier an "invoice for payment" was put in the center of relations with customers as a synonym for "transaction", which is not entirely correct, now "transaction" (contract) is equated to "agreement", and it is necessary to adequately indicate this in all documents.

Features of employee behavior when implementing CRM software.

If implementation of CRM software iscareful and responsible, often it delayed even for several years, despite the assurance of software vendors about a quick and easy "blitzkrieg" in 2-3 months.

The reasons for this delay are outlined above - surprises with the critical importance of the operation of a single chain "client - our company - supplier", misunderstood entities in CRM software itself, destructive behavior of major user groups, misunderstanding of the 
unity of accounting and trading information, exhausting daily synchronization (if software CRM is implemented "separately from accounting"), etc. In addition, in the most cases, especially when CRM software implemented and purchased in a "separate from accounting" format, it turns into a reference database of customers who have at least once worked with our company. Which used mainly for "spam" mailing of advertising offers, letters and promotions to customers, without real connection with daily-concluded agreements, with the dynamics of payments, shipments and procurement plans.

In addition, there is still an erroneous opinion that CRM software needed only for large and medium-sized businesses, while small businesses, because of their insignificance, supposedly do not need CRM at all. For small and micro-businesses, the impact of competent customer management is significantly greater than for medium and large giants. As a rule, there will be nothing special for the "giants" even with a large loss of 5-10\% of customers, which cannot be said about small and micro-businesses. For him, each customer is both important and necessary. In a small business, it is impossible to fill the problem of working with customers with money, simply by hiring new employees - it will be unprofitable. For a small business, CRM software needed, which will be modern, easy, simple, inexpensive and comprehensive.

\section{Conclusions}

With the introduction of CRM, especially cloud based, managers got a tool to streamline their very chaotic activities. The CRM base, which in theory should warn of accumulating problems, identify dangerous trends, implement advanced methods and generally lead the enterprise forward, becomes a bunch of trivial facts.

Since managers mainly work in the CRM system, there is NO a priori in it, there will never be classical financial and managerial accounting, and this is a huge minus. So, as the analysis shows, the use of modern tools in the field of cooperation with clients fosters the innovation of the organization [14].

The idea of integrating CRM with other accounting software also usually fails. Recently, CRM systems have been positioned as an alternative mechanism for achieving the goals of an enterprise, for example, if you look at one of the most advanced and active in the development of CRM systems (regionsoft.ru), there is a hybrid like CRM + financial accounting.

The fallacy of the "customer" category, its extreme narrowness for real application. The concept of "customer", proudly presented to us as the pinnacle of achievement, does not seem to be devoid of deep internal problems. In practice, customers can become counterparties, or other persons, "fall asleep", change their supplier, simultaneously customers of several suppliers. The roles of the buyer, customer, supplier, intermediary, etc., can also change many times, as in general, as well as for these specific transactions. Using the simple and primitive category of "customers" to account for all these facts is very inconvenient. CRM manufacturers try to circumvent these situations by introducing various crutches such as "statuses", "roles", "characteristics", etc. It seems that in the end, the very concept of "customer" (in the sense of a committed customer, follower, etc.) turns into simply "a customer for a given transaction, for a given purchase", just a customer at the current time.

The fallacy is the identification of the category "customer" in the sense of "my (our) customer". The concept of "customer" of the ordinary consumer introduces into a stupor. At this time, the consumer is no one's customer constantly and in full, in contrast to the 6070s. Any housewife who usually buys groceries in at least 3-4 major supermarkets, and also in 2-3 stores near the house, can buy any little thing that can tell you this. Question - whose customer is she? Partial - of all these listed trading establishments. Complete - no one. It 
seems that CRM-systems with their concept of "customer" share the skin of an unkilled bear. The buyer often buys situationally; turning it into a permanent and complete one is worth a lot of energy and a huge expansion of the range, which may not pay off.

Regressive development of CRM systems from business development tools to calculation tools for the manager of "my interest from this customer". CRM systems are slowly turning into calculation tables for the division of interest from customers. Also important is a constant report to the management, which also watches CRM-programs, so that "everything is smooth". All other aspects of their work, implied in their creation, are slowly fading into the background.

The best solution would be to display the "Customers" directly in the "Counterparties" directory (or "Persons") through the subordinate tables "Customer Information", without having to create a separate "Customers" directory. In this case, the "clustomer" will be the predominant "counterparty role" (the value of the "Role" attribute is of the "directory" type). Then the "supplier" will be the predominant role, and the "carrier", and any other roles that further arise in the course of life, as the list of roles is expandable.

\section{Reference}

1. R. Pukala, Engineering Management in Production and Services, 8:3, 43 (2016)

2. R. Pukala, E. Sira, R. Vavrek, Marketing and Management of Innovations, 3, 153 (2018)

3. N. Kurmanov, M. Petrova, S. Suleimenova, IV ${ }^{\text {th }}$ International Innovative Mining Symposium E3S Web of Conferences, 105 (2019)

4. V. Jarmusevica, D. Ilisko, J. Badjanova, V. Jukss, M. Petrova, 19th International Multidisciplinary Scientific GeoConference SGEM, 5:5.3, 645 (2019)

5. Sv. Labunska, M. Petrova, O. Prokopishyna, "Economic Annals - XXI", 165:5-6, (2017)

6. V. Koval, G. Duginets, O. Plekhanova, A. Antonov, M. Petrova, Entrepreneurship and Sustainability, 6:4, 1922 (2019)

7. Yuriy Dyachenko, Nayden Nenkov, Mariana Petrova, Inna Skarga-Bandurova, Oleg Soloviov, Biologically Inspired Cognitive Architectures, Elsevier, 26, 130 (2018)

8. T. Odinokova, M. Bozhinova, M.Petrova, E3S Web Conferences, 41, 04015 (2018)

9. N. Kurmanov, B. Tolysbayev, D. Aibossynova, N. Parmanov, Economic Annals-XXI, 158, 57 (2016)

10. N. Kurmanov, U. Aliev, Sh. Suleimenov, Polish Journal of Management Studies 19:1, 204 (2019)

11. N. Kurmanov, B. Beisengaliyev, A. Dogalov, D. Turekulova, \& N. Kurmankulova, International Journal of Economics and Financial Issues, 6:4, 1440 (2016)

12. N. Kurmanov, D. Turekulova, G. Doskeyeva, \& G. Alina, International Journal of Economics and Financial Issues, 6:3, 907 (2016)

13. A. Kh. Islamgaleyev, N.A. Uruzbayeva, Using a customer-oriented approach in sales management in the metal trading market of the Republic of Kazakhstan (Vienna: Premier Publishing s.r.o. 2018)

14. R. Pukala, M. Petrova, IVth International Innovative Mining Symposium E3S Web of Conferences, 105 (2019) 